\title{
Reduced locus coeruleus integrity linked to response inhibition deficits in parkinsonian disorders
}

Rong Ye ${ }^{1 *}$, Frank H. Hezemans ${ }^{1,2} *$, Claire O'Callaghan ${ }^{3,4}$, Kamen A. Tsvetanov ${ }^{1,5}$, Catarina Rua $^{1}$, P. Simon Jones ${ }^{1}$, Negin Holland ${ }^{1}$, Maura Malpetti ${ }^{1}$, Alexander G. Murley ${ }^{1}$, Roger A. Barker $^{6,7}$, Caroline H. Williams-Gray ${ }^{6}$, Trevor W. Robbins ${ }^{5,8}$, Luca Passamonti ${ }^{1,9 \dagger}$, James B. Rowe $\mathrm{e}^{1,2,8_{\dagger}}$

1) Department of Clinical Neurosciences and Cambridge University Hospitals NHS Trust, University of Cambridge, Cambridge, UK

2) MRC Cognition and Brain Sciences Unit, University of Cambridge, Cambridge, UK

3) Department of Psychiatry, University of Cambridge, Cambridge, UK

4) Brain and Mind Centre and School of Medical Sciences, Faculty of Medicine and Health, University of Sydney, Sydney, Australia

5) Department of Psychology, University of Cambridge, Cambridge, UK

6) John van Geest Centre for Brain Repair, Department of Clinical Neurosciences, University of Cambridge, Cambridge, UK

7) Wellcome - MRC Stem Cell Institute, University of Cambridge, Cambridge, UK

8) Behavioural and Clinical Neuroscience Institute, University of Cambridge, Cambridge, UK

9) Institute of Molecular Bioimaging and Physiology, National Research Council, Milan, Italy

*equal contribution to first authorship

$\dagger$ equal contribution to senior authorship

\section{Corresponding author:}

Rong Ye

Herchel Smith Building for Brain and Mind Sciences

Forvie Site, Robinson Way, Cambridge

CB2 0SZ

United Kingdom

+44 (0) 1223764047

ronye.uk@gmail.com

Running title: LC integrity and response inhibition deficits

Keywords (6): progressive supranuclear palsy, Parkinson's disease, Stop signal task, race model, locus coeruleus, magnetisation transfer imaging 


\section{Abstract}

Parkinson's disease and progressive supranuclear palsy (PSP) both impair response inhibition, exacerbating impulsivity. Inhibitory control deficits vary across individuals, and have been linked with worse prognosis and lack of improvement on dopaminergic therapy. Motor and cognitive control are associated with noradrenergic innervation of the cortex, arising from the locus coeruleus noradrenergic system. Here we test the hypothesis that loss of structural integrity of the locus coeruleus explains response inhibition deficits in progressive supranuclear palsy and Parkinson's disease. This cross-sectional observational study recruited 24 people with idiopathic Parkinson's disease, 14 with PSP-Richardson's syndrome, and 24 age- and sex-matched controls. All participants undertook a stop-signal task and ultrahigh field 7T-magnetic transfer weighted imaging of the locus coeruleus. Hierarchical Bayesian estimation of the parameters of 'race models' of go- versus stop-decisions was used to quantify the cognitive processes of response inhibition. We tested the multivariate relationship between locus coeruleus integrity and model parameters using partial least squares. Both disorders impaired response inhibition at the group level. Progressive supranuclear palsy caused a distinct pattern of abnormalities in inhibitory control, relative to Parkinson's disease and healthy controls, with a paradoxically reduced threshold for go responses, but longer non-decision times, and more lapses of attention. The variation in response inhibition correlated with variation in the integrity of the locus coeruleus, across participants in both clinical groups. Structural imaging of the locus coeruleus, coupled with behavioural modelling in parkinsonian disorders, confirms that locus coeruleus integrity is associated with response inhibition and its degeneration contributes to neurobehavioural changes. The noradrenergic system is therefore a promising target to treat impulsivity in these conditions. The optimisation of noradrenergic treatment is likely to benefit from stratification according to locus coeruleus integrity. 


\section{Introduction}

Progressive supranuclear palsy (PSP) and Parkinson's disease (PD) have distinct neuropathology and clinical features ${ }^{1,2}$, but they can both cause cognitive and behavioural problems ${ }^{3}$. One of the consequences is an impairment of response inhibition, contributing to disinhibited behaviour and impulsivity. These are associated with poor clinical outcomes ${ }^{4-6}$. Impulsivity is a multi-faceted behavioural construct, including abnormal sensitivity to reward, intolerance to delayed reward and a failure to inhibit inappropriate responses ${ }^{7,8}$. These deficits are mediated by abnormalities in complementary frontostriatal neural circuits and neurochemical systems ${ }^{9}$. Here we focus on response inhibition, as the execution of responses represents a point of convergence for upstream changes in cognition and behavioural decisions. Deficits in inhibitory control arise from pathology in frontostriatal circuits, including the ventrolateral prefrontal cortex, pre-motor cortex, caudate and sub-thalamic nuclei, and their monoaminergic regulation. Noradrenergic manipulations influence response inhibition, especially the cancellation of a response, in preclinical models ${ }^{10-12}$, healthy humans ${ }^{13}$, attention deficit disorders ${ }^{14,15}$ and Parkinson's disease ${ }^{16-20}$. They are therefore a promising route to ameliorate response inhibition deficits in diverse neurological and psychiatric disorders.

The locus coeruleus is the main source of noradrenaline in the brain and an early site of pathology in progressive supranuclear palsy and Parkinson's disease ${ }^{21-24}$. Locus coeruleus degeneration is severe in symptomatic progressive supranuclear palsy and Parkinson's disease, although post mortem studies indicate a high degree of variability in locus coeruleus cell loss 24,25 . The heterogeneity in locus coeruleus damage has been linked to variability in the response to drugs that increase noradrenergic transmission such as atomoxetine ${ }^{26}$. To facilitate more targeted treatment of impulsivity in progressive supranuclear palsy and Parkinson's disease, it is necessary to quantify locus coeruleus structural integrity in vivo and determine its relationship to response inhibition. Specialist magnetic resonance imaging (MRI) sequences for ultrahigh field scanners (7T) have enabled sensitive and well-tolerated quantification of locus coeruleus pathology ${ }^{25-28}$. The resolution is sufficient to examine regional effects of pathology within the locus coeruleus ${ }^{29,30}$.

Noradrenergic deficits may influence response inhibition at both motor and cognitive (decisional) levels, given their widespread cortical projections ${ }^{31}$. Response inhibition can be 
measured using performance on a stop signal task, but singular parameters of performance may obscure the complexity of underlying decision mechanisms ${ }^{9,16,18}$. A multivariate model of computational parameters of response inhibition overcomes this limitation, to distinguish motor, attentional and decisional components of inhibition ${ }^{26,32,33}$.

In this study, we used complementary parametric analyses of the stop signal task, estimated with hierarchical Bayesian models, to advance our understanding of the response inhibition deficits in progressive supranuclear palsy and Parkinson's disease. The first model explains response accuracy and reaction times as function of a race between three processes: a stop process, a go process for the response that matches the choice stimulus, and a go process for the response that mismatches the choice stimulus ${ }^{34-36}$. To decompose the cognitive mechanisms of response inhibition, we also parameterised accumulation-to-threshold models in the second type of model, in which evidence accumulates stochastically until a go response threshold is reached. The mean time required to trigger the stop process served as the estimate of the stop signal reaction time (SSRT). The models also estimate attentional failures to trigger the stop and go processes.

We tested the hypothesis that these parameters of response inhibition relate to locus coeruleus structural integrity at an individual patient level, as measured in vivo using 7T MRI. We predicted that the response inhibition deficits characterising progressive supranuclear palsy and Parkinson's disease would be associated with reduced locus coeruleus integrity. Given the multivariate nature of the model parameters and the topographic organisation of the locus coeruleus, we investigated the multivariate relationship between locus coeruleus integrity and response inhibition.

\section{Methods and Materials}

\section{Participants}

Fourteen patients with probable PSP-Richardson's syndrome (MDS 2017 criteria), 24 with idiopathic Parkinson's disease (UK Parkinson's disease Brain Bank criteria), and 24 age- and sex-matched healthy controls were included in the study. Controls did not use psychoactive medications and exclusions criteria for all participants included history of stroke, severe 
medical co-morbidity, and any contraindications to 7T MRI. None of the patients met criteria for impulse control disorders, based on clinical impression and/or the Questionnaire for Impulsive-Compulsive Disorders. Participants were not demented, based on a Mini-Mental State Examination score $>26$ and clinical impression. All patients with Parkinson's disease and 10/14 progressive supranuclear palsy patients were on dopaminergic medications (Table 1). Eighteen patients with Parkinson's disease were part of a single-dose, placebo-controlled, crossover drug study where the relationship between locus coeruleus integrity and drug responsiveness was investigated ${ }^{26}$. The behavioural performance of these patients was examined for the placebo session, and potential placebo or practice effects were explicitly modelled (see Statistical Analyses). All participants underwent a structured clinical, cognitive, and behavioural assessment (Table 1). The study was approved by the local Cambridge Research Ethics Committees. Participants provided written informed consent according to the Declaration of Helsinki.

\section{Stop-signal task}

Response inhibition was measured using a stop-signal paradigm where a two-choice reaction time (RT) 'go' task was occasionally interrupted by a 'stop signal'. For the go task, participants were instructed to indicate the direction of a black arrow presented at the centre of the screen by pressing a left or right button. On stop trials, the arrow changed to a red colour in conjunction with a tone (i.e., the stop signal) and participants were instructed to withhold their initiated response (Fig 1, top-left). The stop signal occurred after a variable delay (i.e., the stop-signal delay, SSD), the length of which was determined by an adaptive staircase method. The SSD ranged from $50 \mathrm{~ms}$ to $1500 \mathrm{~ms}$ and increased or decreased by 50 ms after a successful or failed stop trial, respectively. Further details of the task design are provided in O'Callaghan et al. ${ }^{26}$.

\section{Modelling of response inhibition}

\section{Parametric race models}

We applied two complementary models to the stop-signal task data. The first model assumed that the finish time distributions of the stop and go processes followed ex-Gaussian distributions ${ }^{37}$, with mean $\mu$ and standard deviation $\sigma$ of the Gaussian component, and mean $\tau$ of the exponential component. The mean finish time of each process was estimated as the 
mean of the corresponding ex-Gaussian distribution, which is given by $\mu+\tau$. The mean finish times of the stop process and matching go process were taken as the stop signal reaction time (SSRT) and go RT, respectively.

The second model was similar, except that the finish time distributions of the go processes were assumed to follow shifted Wald distributions ${ }^{36}$. The Wald distribution describes the first-passage time distribution of a single-boundary diffusion process, where evidence accumulates stochastically at a positive mean rate (cf. the drift rate) until a threshold is reached. A subject-specific constant non-decision time shifts the lower bound of the distribution to account for peripheral processes, such as stimulus encoding and motor output. The shifted Wald distribution therefore enables a process model that explains how the go RT distributions were generated.

Both models additionally included the probabilities of attentional failures related to the stop process (trigger failure) and go processes (go failure). Thus, the first model featured 11 free parameters: three ex-Gaussian parameters for each of the three processes, and the trigger and go failure probabilities. The second model featured 9 free parameters: separate drift rates for the matching and mismatching go processes, a threshold and non-decision time that were shared across the go processes, three ex-Gaussian parameters for the stop process, and the trigger and go failure probabilities.

Hierarchical Bayesian modelling was used to fit each model to the observed task data, separately for the progressive supranuclear palsy, Parkinson's disease, and control groups. Markov Chain Monte Carlo (MCMC) sampling methods were used to estimate the posterior distributions of all group- and participant-level parameters. We assigned broad ("weakly informative") priors on the group-level means and standard deviations of the model parameters (Table S1). Sampling convergence was confirmed by visual inspection of the time series plots of the MCMC samples, and by the potential scale reduction statistic R-hat (< 1.1 for all parameters). The absolute goodness of fit was assessed by visually comparing the observed data to simulated data generated from the model's posterior predictive distribution (Fig.S5-7).

Model fitting was performed using the Dynamic Models of Choice (DMC) toolbox ${ }^{38}$ implemented in $\mathrm{R}$ (version 3.6.1). The number of sampling chains was set to three times the 
number of free parameters. Automated procedures were used to continue sampling until convergence was reached (h.run.unstuck.dmc and h.run.converge.dmc functions in the DMC toolbox). After this, an additional 500 iterations were obtained for each chain to create a final posterior distribution for each parameter, which was used for statistical analyses.

\section{MRI acquisition and processing}

Participants were scanned on a 7T Magnetom Terra (Siemens, Erlangen, Germany) with a 32-channel receive head coil (Nova Medical, Wilmington, USA). Following the acquisition and processing protocol described previously ${ }^{26,27}$, the locus coeruleus was imaged using a near-isotropic 3-D magnetisation transfer (MT) weighted sequence at submillimetre resolution $\left(0.4 \times 0.4 \times 0.5 \mathrm{~mm}^{3}, 112\right.$ oblique, axial slices oriented perpendicular to the long axis of the brainstem). Two images with MT presaturation pulses were acquired then averaged off-line to enhance signal-to-noise ratio. One image without MT effect (MT-off) was additionally obtained for registration. A high resolution T1-weighted structural image (0.7 mm isotropic) was acquired using an MP2RAGE sequence with the UK7T Network harmonised protocol ${ }^{39}: \mathrm{TE}=2.58 \mathrm{~ms}, \mathrm{TR}=3500 \mathrm{~ms}, \mathrm{BW}=300 \mathrm{~Hz} / \mathrm{px}$, voxel size $=0.7 \mathrm{x}$ $0.7 \times 0.7 \mathrm{~mm}^{3}, \mathrm{FoV}=224 \times 224 \times 157 \mathrm{~mm}^{3}$, acceleration factor $(\mathrm{A}>>\mathrm{P})=3$, flip angles = $5 / 2^{\circ}$. MT images were bias field corrected then co-registered to the isotropic $0.5 \mathrm{~mm}$ ICBM152 (International Consortium for Brain Mapping) T1-weighted asymmetric nonlinear template ${ }^{40}$ following a T1-driven coregistration approach using the Advanced Normalization Tools (ANTs v2.2.0). The individual registration roadmap was initiated from the estimation between averaged MT image and the MT-off image then moved to the coregistration between MT and T1 modality in the following order: MT-off to MT, individual T1 to MT-off, individual $\mathrm{T} 1$ to $\mathrm{T} 1$ group template and finally $\mathrm{T} 1$ group template to the ICBM152 template.

The co-registered MT images were converted to contrast-to-noise (CNR) maps by subtracting the mean and dividing by the standard deviation of the signal in a central pontine reference region ${ }^{26,27}$. A probabilistic locus coeruleus atlas was applied on the CNR maps with a conservative threshold (25\%) to extract voxel-wise locus coeruleus CNRs for later statistical tests and slice-wise means for group comparisons. Structural T1-weighted images were subjected to FreeSurfer (v 6.0) recon-all pipeline with -highres and -brainstem options. The 
resulting total intracranial and brainstem volumes were used for the estimation of global and local atrophy, respectively.

\section{Statistical Analysis}

\section{Group differences in response inhibition parameters}

The go error rate was defined as the proportion of go trials with an incorrect response, including commission errors (responses that mismatched the choice stimulus) and omission errors (missing responses). The stop accuracy rate was defined as the proportion of stop trials with successfully inhibited (i.e. missing) responses. Each of these measures served as dependent variables in an ANOVA with group as the between-subjects factor. Differences between specific groups were then examined with post-hoc Tukey's tests.

We focused on group differences by examining the posterior distributions of the group-level means of the race model parameters. For each posterior distribution, we took the median as the posterior estimate, and the $95 \%$ quantile interval (QI) as the range of plausible values. We derived posterior distributions for group contrasts by subtracting the set of MCMC samples of the two groups under consideration. For each group contrast, we computed the probability of direction $\left(P_{\text {dir }}\right)$ as an index of the presence of an effect ${ }^{41}$. This measure indicates the proportion of the contrast's posterior distribution that is strictly positive or negative (whichever is the most probable). Note that $P_{\text {dir }}$ can be directly interpreted as the probability that a group difference is non-zero, and is therefore not subject to a particular significance threshold. To examine individual differences in mechanisms of response inhibition, we extracted the medians of all participant-level posterior distributions.

\section{The relationship between locus coeruleus integrity and response inhibition}

We studied the relationship between locus coeruleus integrity and response inhibition deficits with a two-level analytical strategy ${ }^{42,43}$. First, the multidimensional relationship was examined using partial least squares (PLS) ${ }^{42,44}$ with in-house Matlab (R2018b) scripts where pairs of latent variables were computed from all response inhibition parameters $\left(\mathrm{LV}_{\text {inhibition }}\right)$ and voxelwise locus coeruleus contrast $\left(\mathrm{LV}_{\mathrm{LC}}\right)$. The PLS multivariate method is particularly 
suitable given the ratio of variables to participants ${ }^{45}$. The significant pair of latent variables was identified using a permutation test $(10,000$ iterations, $P<0.05)$.

Second, individual loadings on LVs were subjected to linear regression models to confirm the group-wise relationship between locus coeruleus integrity and response inhibition ability. Subsequent regression models examined the effects of nuisance covariates including age, global and local atrophy, disease duration and motor severity. To mitigate the potential placebo and/or practice effects in the 18/24 of the patients with Parkinson's disease who had completed the task as part of a drug study ${ }^{26}$, we adopted two approaches using (i) a categorical variable indicating session $(0=$ first / only session; $1=$ second session $)$ and (ii) a categorical indicator for drug order $(0=$ one session without placebo; $1=$ first session on placebo; 2 = second session on placebo). Adding these categorical indicators as a covariate of no interest in the regression models did not meaningfully change the relationship between locus coeruleus integrity and response inhibition (see results). Prior to analysis, continuous variables were z-scored and categorical variables (including nuisance covariates) were assigned sum-to-zero contrasts.

\section{Results}

\section{Basic task performance}

Participant characteristics and clinical summary data are presented in Table 1. Groups were similar by age, sex and education, while the patient groups were similar by disease duration and motor severity, although cognitive function was lower in progressive supranuclear palsy. There were expected significant main effects of group on both the stop accuracy rate (Fig.2A; $\left.F_{(2,59)}=10.21, P<.001 ; B F=143.66\right)$ and go error rate $\left(\right.$ Fig. $2 D ; F_{(2,59)}=8.46, P<.001 ; B F$ $=46.85)$. Post hoc tests indicated that these effects were driven by patients with progressive supranuclear palsy, who had reduced response accuracy compared to the other groups.

The mean go RT (Fig.2E) was similar across progressive supranuclear palsy (median $=1.08 \mathrm{~s}$, 95\% QI: $[0.80,1.29])$, Parkinson's disease (median $=0.97$ s, 95\% QI: [0.36, 1.30]), and control (median $=1.00$ s, 95\% QI: $[0.23,1.43])$ groups $($ Fig.2F). However, the mean SSRT was longer in progressive supranuclear palsy (Fig.2B; median $=0.60$ s, 95\% QI: [0.51, 0.69]) compared to controls (Fig.2C; median $=0.39$ s, 95\% QI: [0.36, 0.42]; $\Delta$ PSP - controls: 
median $=0.21 \mathrm{~s}, 95 \%$ QI: $\left.[0.11,0.30], P_{\mathrm{dir}}=99.98 \%\right)$ and Parkinson's disease (median $=0.43$ s, 95\% QI: [0.39, 0.48]; $\triangle$ PSP - PD: median $=0.16$ s, 95\% QI: [0.06, 0.27], $P_{\text {dir }}=99.90 \%$ ), confirming the expected impairment of response inhibition. The SSRT was also longer in Parkinson's disease compared to controls (Fig.2B; $\Delta$ PD - controls: median $=0.04$ s, 95\% QI: $\left.[-0.01,0.10], P_{\mathrm{dir}}=94.01 \%\right)$.

\section{Processes underlying response inhibition deficits}

Following Zhang et al (2015), the mean threshold height was confirmed as lower in progressive supranuclear palsy (Fig.3A; median $=2.17,95 \%$ QI: $[1.93,2.40])$ relative to controls (Fig.3B; median $=3.31,95 \%$ QI: [2.69, 3.80]; $\triangle$ PSP - controls: median $=-1.14,95 \%$ QI: [-1.68, -0.49], $\left.P_{\text {dir }}=99.71 \%\right)$ and Parkinson's disease (median $=3.02,95 \%$ QI: [2.38, 3.53]; $\triangle$ PSP - PD: median $=-0.85,95 \%$ QI: [-1.41, -0.18], $\left.P_{\text {dir }}=98.99 \%\right)$. The non-decision time was slower in progressive supranuclear palsy (Fig.3C; median $=0.22$ s, 95\% QI: [0.11, 0.34]) relative to controls (Fig.3D; median $=0.11 \mathrm{~s}$, 95\% QI: [0.10, 0.13]; $\Delta$ PSP - controls: median $=0.11 \mathrm{~s}, 95 \%$ QI: [-0.004, 0.23], $\left.P_{\text {dir }}=96.37 \%\right)$ and Parkinson's disease (median $=$ 0.12 s, 95\% QI: [0.10, 0.16]; $\Delta$ PSP - PD: median $=0.10 \mathrm{~s}, 95 \%$ QI: $[-0.02,0.22], P_{\text {dir }}=$ 93.67\%). However, the posterior estimate of progressive supranuclear palsy patients' nondecision time was imprecise (Fig.3C), suggesting that a slower non-decision time was not a feature across all patients with progressive supranuclear palsy.

We estimated the probabilities of failing to trigger the stop process (trigger failure) and go processes (go failure). The mean probit-transformed trigger failure probability was higher in progressive supranuclear palsy (Fig.4A; median $=-1.78,95 \%$ QI: [-2.68, -0.87]) compared to controls (Fig.4B; median $=-3.06,95 \%$ QI: $[-3.71,-2.40]$; $\triangle$ PSP - controls: median $=1.27$, 95\% QI: $\left.[0.18,2.40], P_{\mathrm{dir}}=98.85 \%\right)$. The mean probit-transformed go failure probability was higher in the progressive supranuclear palsy group $($ Fig.4C; median $=-2.78,95 \%$ QI: [-3.12, -2.40]) compared to the control (Fig.4D; median $=-3.74,95 \%$ QI: [-4.13, -3.35]; $\triangle$ PSP controls: median $=0.96,95 \%$ QI: $\left.[0.45,1.49], P_{\text {dir }}=99.98 \%\right)$ and Parkinson's disease group (median $=-3.46,95 \%$ QI: [-3.81, -3.12]; $\Delta$ PSP - PD: median $=0.69,95 \%$ QI: $[0.21,1.19]$, $P_{\text {dir }}=99.76 \%$ ). There were no meaningful differences between the Parkinson's disease and control groups on these attentional parameters (Fig.4B \&D; all $\left.P_{\mathrm{dir}}<90 \%\right)$. 


\section{Locus coeruleus integrity and individual differences}

The locus coeruleus integrity was reduced in the caudal region for both patient groups

(Fig.S1-S4; Fig.5C). Partial least squares analysis (PLS) of the response inhibition parameters and voxel-wise locus coeruleus contrast identified a single significant pair of latent variables $(r=0.75, P=.040,10,000$ permutations $)$.

The locus coeruleus latent variable $\left(\mathrm{LV}_{\mathrm{LC}}\right)$ expressed negative loadings throughout the structure, to a variable degree across sub-regions (Fig.5A). The response inhibition latent variable $\left(\mathrm{LV}_{\text {inhibition}}\right)$ expressed positive loadings on the SSRT, go and trigger failure probabilities, and non-decision time, and expressed negative loadings on the drift rate and response threshold of the go process (Fig.5B). Thus, higher scores on this behavioural latent variable reflected impaired response inhibition with prolonged SSRT, greater probability of attentional failures, reduced response threshold, lower drift rate, and longer non-decision time.

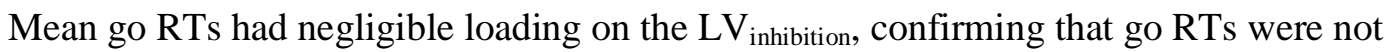
related to the cognitive mechanisms of response inhibition.

A regression analysis examined the relationship between response inhibition and locus coeruleus integrity, and potential group differences. The $\mathrm{LV}_{\text {inhibition }}$ participant score was the dependent variable, and the $\mathrm{LV}_{\mathrm{LC}}$ participant score, group, and their interaction were independent variables. There was a significant overall relationship between the $\mathrm{LV}_{\mathrm{LC}}$ scores and the $\mathrm{LV}_{\text {inhibition }}$ scores (Fig.5D; $\left.\beta=-0.24, \mathrm{~F}(1,56)=7.23, P=.009 ; \mathrm{BF}=6.95\right)$. This suggests that individuals with reduced locus coeruleus integrity have more severe deficits in response inhibition. There was a significant main effect of group on the $\mathrm{LV}_{\text {inhibition }}$ scores $\left(F_{(2}\right.$, 56) $=29.88, P<.001 ; B F=1.98 \times 10^{7}$ ), reflecting impaired response inhibition in the progressive supranuclear palsy group compared to the control group $\left(t_{(56)}=7.46, P<.001\right)$ and PD group $\left(t_{(56)}=6.33, P<.001\right)$, regardless of locus coeruleus CNR. There was no significant interaction effect between the $\mathrm{LV}_{\mathrm{LC}}$ scores and group $\left(F_{(2,56)}=0.31, P=.734 ; B F\right.$ $=0.15)$, suggesting that the slope between the $\mathrm{LV}_{\mathrm{LC}}$ and $\mathrm{LV}_{\text {inhibition }}$ scores is similar across groups.

We confirmed the robustness of these results with four additional regression analyses. First, adding age, gender, and years of education to the regression model as covariates of no interest did not meaningfully change the relationship between the $\mathrm{LV}_{\mathrm{LC}}$ and $\mathrm{LV}_{\text {inhibition }}$ scores 
$\left(ß=-0.23, F_{(1,53)}=6.31, P=.015 ; B F=6.99\right)$, nor did the inclusion of additional covariates, including disease duration, motor severity, and local and global brain atrophy. Model selection procedures consistently identified a relatively sparse model as the optimal account of the data, retaining only the $\mathrm{LV}_{\mathrm{LC}}$ scores and group as predictors of $L V_{\text {inhibition }}$ (Table S2-5). Third, re-running the regression analysis with only the Parkinson's disease and progressive supranuclear palsy groups yielded a similar relationship between the $L V_{L C}$ and $L V_{\text {inhibition }}$ scores $\left(B=-0.26, F_{(1,34)}=4.90, P=.034 ; B F=2.07\right.$; Table S6). Fourth, accounting for potential placebo and / or practice effects in the Parkinson's disease group did not meaningfully change the results (Table S7-8). 


\section{Discussion}

This study confirms the hypothesis that response inhibition deficits in Parkinson's disease and progressive supranuclear palsy are linked to reduced structural integrity of the locus coeruleus, the principal source of cerebral noradrenaline. Diminished response inhibition (i.e., multivariate disinhibition-related parameters) was associated with reduced locus coeruleus integrity (i.e., multivariate voxelwise loadings) across all groups, in keeping with psychopharmacological and pre-clinical studies ${ }^{10,11,16-20,46}$.

The race models identified latent variables to explain the behavioural performance. Despite similar mean reaction times in the go responses, there were disease-specific patterns underlying abnormal inhibitory control. Patients with progressive supranuclear palsy had a reduced response threshold, consistent with a paradoxical bias towards committing go responses as proposed by Zhang et al. ${ }^{32}$, noting that the current study was manual not oculomotor. The progressive supranuclear palsy group also had a slower non-decision time, suggesting they required more time for sensory encoding and execution of motor outputs. There was evidence for a lower drift rate among patients with progressive supranuclear palsy relative to patients with Parkinson's disease and controls, confirming the slower accumulation of evidence to reach a decision.

Task performance might also have been influenced by attentional problems, which are a common cognitive feature in parkinsonian disorders, especially in progressive supranuclear palsy $^{3}$. To account for this possibility, we included attentional failures related to the stop and go processes (i.e., trigger failure and go failure) in the race models of the stop signal task. These indices revealed that patients with progressive supranuclear palsy had greater attentional deficits than Parkinson's disease and control groups, albeit not to the extent that prevented them from correctly executing the task. The attentional impairments during the Stop/Go paradigm were also captured within the main PLS-derived $\mathrm{LV}_{\text {inhibition variable that }}$ related to the $\mathrm{LV}_{\mathrm{LC}}$ component reflecting locus coeruleus structural integrity.

The results support the hypothesis that the decision threshold is reduced in progressive supranuclear palsy to compensate for the impairment in evidence accumulation (reduced drift rate) and execution (slower non-decision time). This threshold compensation is liable to change the quality of decisions, and thereby promote impulsivity. This relationship is disease 
agnostic and relates to the level of pathology with the locus coeruleus which is more severely affected in progressive supranuclear palsy ${ }^{25}$.

The variability of locus coeruleus degeneration across patients in our study is also evident post mortem ${ }^{21,22,24}$, consistent with what is observed in other neurodegenerative disorders such as Alzheimer's disease, corticobasal degeneration and Lewy Body dementia ${ }^{47-50}$. This highlights the potential of locus coeruleus imaging as a trans-diagnostic marker, to understand individual differences in cognition beyond the classic nosological borders and diagnostic criteria ${ }^{51}$.

On average, locus coeruleus degeneration is more severe in progressive supranuclear palsy than Parkinson's disease, and our in vivo imaging data confirms this, particularly in the caudal portions ${ }^{25}$. This distribution is consistent with neuropathological studies reporting greater degeneration in the caudal locus coeruleus ${ }^{52}$. However, the response inhibition deficits spanning progressive supranuclear palsy and Parkinson's disease topographically map to the mid-caudal and rostral locus coeruleus, that innervate the forebrain regions associated with response inhibition and impulsive behaviour ${ }^{30}$.

The locus coeruleus-noradrenergic system's influence on response inhibition and impulsivity may be non-linear (e.g. a U-inverted shape function), and involve multiple brain networks $10,11,53$. The locus coeruleus diffusely projects to many sites within the brain where noradrenaline has a state-dependant effect on the neuronal input-output gain function ${ }^{54}$. Although we did not directly measure noradrenaline transmission or noradrenergic receptor density, locus coeruleus structural integrity is a proxy index of noradrenergic function ${ }^{51,55}$.

Our study focused on noradrenergic contributions to response inhibition deficits in parkinsonian disorders. However, we recognise that noradrenergic projections from the locus coeruleus have secondary pharmacological interactions with other neurotransmitter systems, including dopamine and GABA. For example, dopamine and noradrenaline can be coreleased from the same LC-noradrenergic terminals ${ }^{56-58}$. Locus coeruleus activity can alter midbrain dopamine cell firing ${ }^{59}$ and directly participate in the regulation of dopamine release in hippocampus ${ }^{60}$. Nevertheless, pharmacological studies using selective dopamine manipulations have found no effects on response inhibition ${ }^{61-63}$, and there is no clear evidence for a relationship between response inhibition and the levodopa equivalent daily dose or the 
on/off state of dopaminergic medication in Parkinson's disease ${ }^{64,65}$. Taken together, our results are consistent with a growing body of work that indicates a robust link between the locus-coeruleus noradrenaline system and response inhibition, although further work is needed to elucidate the potential contribution of dopaminergic mechanisms.

However, we anticipate that any future use of noradrenergic treatments that target response inhibition deficits would be adjunctive to standard dopaminergic therapy, and not an alternative. Therefore, all patients were tested on their usual clinically optimised dopaminergic medication. We acknowledge that patients' task performance may have differed if they were taken off their dopaminergic medication, which consequently could have affected the relationship between response inhibition and locus coeruleus integrity.

Our study has several limitations. We acknowledge that all the patients were diagnosed with clinical criteria, without pathological confirmation. Misclassification of progressive supranuclear palsy subtypes and other atypical parkinsonian syndromes can occur for PSPRichardson's syndrome diagnosis ${ }^{66}$ and future studies including post-mortem confirmation would be critical to enhance the diagnostic accuracy. Data from some patients with Parkinson's disease are drawn from a placebo-controlled drug study ${ }^{26}$. Only the placebo data were analysed, but we acknowledge that this might have resulted in heterogeneity due to effects of placebo expectancy and/or task practice. To mitigate these issues, we used two approaches to explicitly model the impact of placebo/practice confounds in the statistical analyses. Reassuringly, neither of these steps meaningfully altered the results.

To conclude, our study further elucidates the role of the locus coeruleus noradrenergic contribution in response inhibition and its impairment in Parkinson's disease and Progressive Supranuclear Palsy. We propose that locus coeruleus imaging could be used as a heuristic stratification marker in clinical trials, targeting response inhibition deficits with noradrenergic drugs in those most likely to benefit. Individual differences in response to drug are marked ${ }^{26}$, due to variation in disease severity, allelic variations in the noradrenaline transporter, polymorphisms in the CYP2D6 liver enzyme catabolising noradrenergic drugs, baseline brain networks structure or function, and the integrity of the locus coeruleus $16,17,20,26,46,67,68$. Optimisation of noradrenergic treatments will benefit from better understanding the mechanisms of response inhibition and their relationship to the integrity of the locus coeruleus. 
medRxiv preprint doi: https://doi.org/10.1101/2021.10.14.21264996; this version posted October 16, 2021. The copyright holder for this preprint (which was not certified by peer review) is the author/funder, who has granted medRxiv a license to display the preprint in perpetuity.

It is made available under a CC-BY 4.0 International license. 


\section{Acknowledgements}

This study was supported by Parkinson's UK (K-1702); the Cambridge Centre for ParkinsonPlus; the China Scholarship Council; a Neil Hamilton Fairley Fellowship from the Australian National Health and Medical Research Council (GNT1091310); a Cambridge Trust ViceChancellor's Award and Fitzwilliam College Scholarship; the Association of British Neurologists - Patrick Berthoud Charitable Trust (RG99368); the Medical Research Council (SUAG/051 G101400; MR/P01271X/1); James S. McDonnell Foundation 21st Century Science Initiative Scholar Award in Understanding Human Cognition; a RCUK/UKRI Research Innovation Fellowship awarded by the Medical Research Council (MR/R007446/1); the NIHR Cambridge Clinical Research Facility and the NIHR Cambridge Biomedical Research Centre (BRC-1215-20014). The views expressed are those of the authors and not necessarily those of the NHS, the NIHR or the Department of Health and Social Care. For the purpose of open access, the author has applied a CC BY public copyright licence to any Author Accepted Manuscript version arising from this submission.

\section{Disclosures}

The authors declared no conflict of interest. 


\section{References}

1. Braak H, Del Tredici K, Rub U, de Vos RA, Jansen Steur EN, Braak E. Staging of brain pathology related to sporadic Parkinson's disease. Neurobiol Aging. Mar-Apr 2003;24(2):197-211.

doi:10.1016/s0197-4580(02)00065-9

2. Hauw JJ, Daniel SE, Dickson D, et al. Preliminary NINDS neuropathologic criteria for Steele-Richardson-Olszewski syndrome (progressive supranuclear palsy). Neurology. Nov 1994;44(11):2015-9. doi:10.1212/wnl.44.11.2015

3. Rittman T, Ghosh BC, McColgan P, et al. The Addenbrooke's Cognitive Examination for the differential diagnosis and longitudinal assessment of patients with parkinsonian disorders. J Neurol Neurosurg Psychiatry. May 2013;84(5):544-51. doi:10.1136/jnnp-2012-303618 4. Ryu DW, Kim JS, Yoo SW, Oh YS, Lee KS. The Impact of Impulsivity on Quality of Life in Early Drug-Naive Parkinson's Disease Patients. J Mov Disord. Sep 2019;12(3):172-176.

doi:10.14802/jmd.19004

5. Erga AH, Alves G, Tysnes OB, Pedersen KF. Impulsive and compulsive behaviors in Parkinson's disease: Impact on quality of and satisfaction with life, and caregiver burden. Parkinsonism Relat Disord. Sep 2020;78:27-30. doi:10.1016/j.parkreldis.2020.07.007

6. Murley AG, Rouse MA, Coyle-Gilchrist ITS, et al. Predicting loss of independence and mortality in frontotemporal lobar degeneration syndromes. J Neurol Neurosurg Psychiatry. Feb 9 2021 ; doi:10.1136/jnnp-2020-324903

7. Dalley JW, Robbins TW. Fractionating impulsivity: neuropsychiatric implications. Nat Rev Neurosci. Feb 17 2017;18(3):158-171. doi:10.1038/nrn.2017.8

8. Dalley JW, Everitt BJ, Robbins TW. Impulsivity, compulsivity, and top-down cognitive control. Neuron. Feb 24 2011;69(4):680-94. doi:10.1016/j.neuron.2011.01.020

9. Passamonti L, Lansdall CJ, Rowe JB. The neuroanatomical and neurochemical basis of apathy and impulsivity in frontotemporal lobar degeneration. Curr Opin Behav Sci. Aug 2018;22:14-20. doi:10.1016/j.cobeha.2017.12.015

10. Bari A, Mar AC, Theobald DE, et al. Prefrontal and monoaminergic contributions to stop-signal task performance in rats. J Neurosci. Jun 22 2011;31(25):9254-63. doi:10.1523/JNEUROSCI.1543-11.2011

11. Bari A, Robbins TW. Inhibition and impulsivity: behavioral and neural basis of response control. Prog Neurobiol. Sep 2013;108:44-79. doi:10.1016/j.pneurobio.2013.06.005 
medRxiv preprint doi: https://doi.org/10.1101/2021.10.14.21264996; this version posted October 16, 2021. The copyright holder for this preprint (which was not certified by peer review) is the author/funder, who has granted medRxiv a license to display the preprint in perpetuity. It is made available under a CC-BY 4.0 International license .

12. Robinson ES, Eagle DM, Mar AC, et al. Similar effects of the selective noradrenaline reuptake inhibitor atomoxetine on three distinct forms of impulsivity in the rat. Neuropsychopharmacology. Apr 2008;33(5):1028-37. doi:10.1038/sj.npp.1301487

13. Chamberlain SR, Hampshire A, Muller U, et al. Atomoxetine modulates right inferior frontal activation during inhibitory control: a pharmacological functional magnetic resonance imaging study. Biol Psychiatry. Apr 1 2009;65(7):550-5. doi:10.1016/j.biopsych.2008.10.014 14. Chamberlain SR, Del Campo N, Dowson J, et al. Atomoxetine improved response inhibition in adults with attention deficit/hyperactivity disorder. Biol Psychiatry. Nov 1 2007;62(9):977-84.

doi:10.1016/j.biopsych.2007.03.003

15. Del Campo N, Chamberlain SR, Sahakian BJ, Robbins TW. The roles of dopamine and noradrenaline in the pathophysiology and treatment of attention-deficit/hyperactivity disorder. Biol Psychiatry. Jun 15 2011;69(12):e145-57. doi:10.1016/j.biopsych.2011.02.036 16. Ye Z, Altena E, Nombela $C$, et al. Improving response inhibition in Parkinson's disease with atomoxetine. Biol Psychiatry. Apr 15 2015;77(8):740-8. doi:10.1016/j.biopsych.2014.01.024

17. Ye Z, Rae CL, Nombela C, et al. Predicting beneficial effects of atomoxetine and citalopram on response inhibition in Parkinson's disease with clinical and neuroimaging measures. Hum Brain Mapp. Mar 2016;37(3):1026-37. doi:10.1002/hbm.23087

18. Kehagia AA, Housden CR, Regenthal R, et al. Targeting impulsivity in Parkinson's disease using atomoxetine. Brain. Jul 2014;137(Pt 7):1986-97. doi:10.1093/brain/awu117

19. Averbeck BB, O'Sullivan SS, Djamshidian A. Impulsive and compulsive behaviors in Parkinson's disease. Annu Rev Clin Psychol. 2014;10:553-80. doi:10.1146/annurev-clinpsy-032813-153705 20. Borchert RJ, Rittman T, Passamonti L, et al. Atomoxetine Enhances Connectivity of Prefrontal Networks in Parkinson's Disease. Neuropsychopharmacology. Jul 2016;41(8):2171-7. doi:10.1038/npp.2016.18

21. Cash R, Dennis T, L'Heureux R, Raisman R, Javoy-Agid F, Scatton B. Parkinson's disease and dementia: norepinephrine and dopamine in locus ceruleus. Neurology. Jan 1987;37(1):42-6. doi:10.1212/wnl.37.1.42

22. Zweig RM, Cardillo JE, Cohen M, Giere S, Hedreen JC. The locus ceruleus and dementia in Parkinson's disease. Neurology. May 1993;43(5):986-91. doi:10.1212/wnl.43.5.986

23. Li Y, Wang C, Wang J, et al. Mild cognitive impairment in de novo Parkinson's disease: A neuromelanin MRI study in locus coeruleus. Mov Disord. Jun 2019;34(6):884-892. doi:10.1002/mds.27682 
medRxiv preprint doi: https://doi.org/10.1101/2021.10.14.21264996; this version posted October 16, 2021. The copyright holder for this preprint (which was not certified by peer review) is the author/funder, who has granted medRxiv a license to display the preprint in perpetuity. It is made available under a CC-BY 4.0 International license .

24. Kaalund SS, Passamonti L, Allinson KSJ, et al. Locus coeruleus pathology in progressive supranuclear palsy, and its relation to disease severity. Acta Neuropathol Commun. Feb 4 2020;8(1):11.

doi:10.1186/s40478-020-0886-0

25. Ye R, O'Callaghan C, Rua C, et al. Locus Coeruleus Integrity from 7T MRI Relates to Apathy and Cognition in Parkinson's Disease and Progressive Supranuclear Palsy. 2021;

26. O'Callaghan C, Hezemans FH, Ye R, et al. Locus coeruleus integrity and the effect of atomoxetine on response inhibition in Parkinson's disease. Brain. Mar 30 2021;doi:10.1093/brain/awab142 27. Ye R, Rua C, O'Callaghan C, et al. An in vivo probabilistic atlas of the human locus coeruleus at ultra-high field. Neuroimage. Jan 15 $2021 ; 225: 117487$. doi:10.1016/j.neuroimage.2020.117487

28. Wang J, Li Y, Huang Z, et al. Neuromelanin-sensitive magnetic resonance imaging features of the substantia nigra and locus coeruleus in de novo Parkinson's disease and its phenotypes. Eur J Neurol. Jul 2018;25(7):949-e73. doi:10.1111/ene.13628

29. Mason ST, Fibiger HC. Regional topography within noradrenergic locus coeruleus as revealed by retrograde transport of horseradish peroxidase. J Comp Neurol. Oct 15 1979;187(4):703-24. doi:10.1002/cne.901870405

30. Loughlin SE, Foote SL, Bloom FE. Efferent projections of nucleus locus coeruleus: topographic organization of cells of origin demonstrated by three-dimensional reconstruction. Neuroscience. Jun 1986;18(2):291306. doi:10.1016/0306-4522(86)90155-7

31. Sara SJ. The locus coeruleus and noradrenergic modulation of cognition. Nat Rev Neurosci. Mar 2009;10(3):211-23.

doi:10.1038/nrn2573

32. Zhang J, Rittman T, Nombela C, et al. Different decision deficits impair response inhibition in progressive supranuclear palsy and Parkinson's disease. Brain. Jan 2016;139(Pt 1):161-73.

doi:10.1093/brain/awv331

33. Murley AG, Rouse MA, Jones PS, et al. GABA and glutamate deficits from frontotemporal lobar degeneration are associated with disinhibition. Brain. Dec 5 2020;143(11):3449-3462.

doi:10.1093/brain/awaa305

34. Logan GD, Cowan WB, Davis KA. On the ability to inhibit simple and choice reaction time responses: a model and a method. $J$ Exp Psychol Hum Percept Perform. Apr 1984;10(2):276-91. doi:10.1037//0096-1523.10.2.276

35. Matzke D, Curley S, Gong CQ, Heathcote A. Inhibiting responses to difficult choices. J Exp Psychol Gen. Jan 2019;148(1):124-142. doi:10.1037/xge0000525 
medRxiv preprint doi: https://doi.org/10.1101/2021.10.14.21264996; this version posted October 16, 2021. The copyright holder for this preprint (which was not certified by peer review) is the author/funder, who has granted medRxiv a license to display the preprint in perpetuity. It is made available under a CC-BY 4.0 International license .

36. Matzke D, Logan GD, Heathcote AJCB, Behavior. A cautionary note on evidence-accumulation models of response inhibition in the stop-signal paradigm. 2020;3(3):269-288.

37. Heathcote A, Popiel SJ, Mewhort DJPb. Analysis of response time distributions: An example using the Stroop task. 1991;109(2):340.

38. Heathcote A, Lin YS, Reynolds A, Strickland L, Gretton M, Matzke D. Dynamic models of choice. Behav Res Methods. Apr 2019;51(2):961985. doi:10.3758/s13428-018-1067-y

39. Clarke WT, Mougin O, Driver ID, et al. Multi-site harmonization of 7 tesla MRI neuroimaging protocols. Neuroimage. Feb 1 2020;206:116335. doi:10.1016/j.neuroimage.2019.116335

40. Fonov V, Evans AC, Botteron K, et al. Unbiased average ageappropriate atlases for pediatric studies. Neuroimage. Jan 1 2011;54(1):313-27. doi:10.1016/j.neuroimage.2010.07.033

41. Makowski D, Ben-Shachar MS, Chen SHA, Ludecke D. Indices of Effect Existence and Significance in the Bayesian Framework. Front Psychol. 2019;10:2767. doi:10.3389/fpsyg.2019.02767

42. Tsvetanov KA, Gazzina S, Jones PS, et al. Brain functional network integrity sustains cognitive function despite atrophy in presymptomatic genetic frontotemporal dementia. Alzheimers Dement. Mar 2021;17(3):500-514. doi:10.1002/alz.12209

43. Passamonti L, Tsvetanov KA, Jones PS, et al. Neuroinflammation and Functional Connectivity in Alzheimer's Disease: Interactive Influences on Cognitive Performance. J Neurosci. Sep 4 2019;39(36):7218-7226. doi:10.1523/JNEUROSCI.2574-18.2019 44. Krishnan A, Williams LJ, Mclntosh AR, Abdi H. Partial Least Squares (PLS) methods for neuroimaging: a tutorial and review. Neuroimage. May 15 2011;56(2):455-75.

doi:10.1016/j.neuroimage.2010.07.034

45. Grellmann C, Bitzer S, Neumann J, et al. Comparison of variants of canonical correlation analysis and partial least squares for combined analysis of MRI and genetic data. Neuroimage. Feb 15 2015;107:289310. doi:10.1016/j.neuroimage.2014.12.025

46. Ye Z, Altena E, Nombela C, et al. Selective serotonin reuptake inhibition modulates response inhibition in Parkinson's disease. Brain. Apr 2014;137(Pt 4):1145-55. doi:10.1093/brain/awu032

47. Brunnstrom H, Friberg N, Lindberg E, Englund E. Differential degeneration of the locus coeruleus in dementia subtypes. Clin Neuropathol. May-Jun 2011;30(3):104-10. doi:10.5414/npp30104 48. Theofilas P, Ehrenberg AJ, Dunlop S, et al. Locus coeruleus volume and cell population changes during Alzheimer's disease progression: A stereological study in human postmortem brains with 
medRxiv preprint doi: https://doi.org/10.1101/2021.10.14.21264996; this version posted October 16, 2021. The copyright holder for this preprint (which was not certified by peer review) is the author/funder, who has granted medRxiv a license to display the preprint in perpetuity. It is made available under a CC-BY 4.0 International license .

potential implication for early-stage biomarker discovery. Alzheimers Dement. Mar 2017;13(3):236-246. doi:10.1016/j.jalz.2016.06.2362 49. Betts MJ, Cardenas-Blanco A, Kanowski M, et al. Locus coeruleus $\mathrm{MRI}$ contrast is reduced in Alzheimer's disease dementia and correlates with CSF Abeta levels. Alzheimers Dement (Amst). Dec 2019;11:281285. doi:10.1016/j.dadm.2019.02.001

50. Eser RA, Ehrenberg AJ, Petersen C, et al. Selective Vulnerability of Brainstem Nuclei in Distinct Tauopathies: A Postmortem Study. $J$ Neuropathol Exp Neurol. Feb 1 2018;77(2):149-161.

doi:10.1093/jnen/nlx113

51. Betts MJ, Kirilina E, Otaduy MCG, et al. Locus coeruleus imaging as a biomarker for noradrenergic dysfunction in neurodegenerative diseases. Brain. Sep 1 2019;142(9):2558-2571.

doi:10.1093/brain/awz193

52. Bertrand E, Lechowicz W, Szpak GM, Dymecki J. Qualitative and quantitative analysis of locus coeruleus neurons in Parkinson's disease. Folia Neuropathol. 1997;35(2):80-6.

53. Cools R, D'Esposito M. Inverted-U-shaped dopamine actions on human working memory and cognitive control. Biol Psychiatry. Jun 15 $2011 ; 69(12): \mathrm{e} 113-25$. doi:10.1016/j.biopsych.2011.03.028

54. Shine JM, Muller EJ, Munn B, Cabral J, Moran RJ, Breakspear M. Computational models link cellular mechanisms of neuromodulation to large-scale neural dynamics. Nat Neurosci. May 6 2021;doi:10.1038/s41593-021-00824-6

55. Sommerauer M, Fedorova TD, Hansen AK, et al. Evaluation of the noradrenergic system in Parkinson's disease: an 11C-MeNER PET and neuromelanin MRI study. Brain. Feb 1 2018;141(2):496-504.

doi:10.1093/brain/awx348

56. Devoto P, Flore G, Pani L, Gessa GL. Evidence for co-release of noradrenaline and dopamine from noradrenergic neurons in the cerebral cortex. Mol Psychiatry. Nov $2001 ; 6(6): 657-64$.

doi:10.1038/sj.mp.4000904

57. Devoto P, Flore G, Saba P, Fa M, Gessa GL. Co-release of noradrenaline and dopamine in the cerebral cortex elicited by single train and repeated train stimulation of the locus coeruleus. BMC Neurosci. May 2 2005;6:31. doi:10.1186/1471-2202-6-31

58. Devoto P, Flore G, Saba P, Fa M, Gessa GL. Stimulation of the locus coeruleus elicits noradrenaline and dopamine release in the medial prefrontal and parietal cortex. $J$ Neurochem. Jan 2005;92(2):368-74. doi:10.1111/j.1471-4159.2004.02866.x

59. Mejias-Aponte CA. Specificity and impact of adrenergic projections to the midbrain dopamine system. Brain Res. Jun 15 2016;1641(Pt

B):258-73. doi:10.1016/j.brainres.2016.01.036 
60. Duszkiewicz AJ, McNamara CG, Takeuchi T, Genzel L. Novelty and Dopaminergic Modulation of Memory Persistence: A Tale of Two Systems. Trends Neurosci. Feb 2019;42(2):102-114. doi:10.1016/j.tins.2018.10.002 61. Bari A, Eagle DM, Mar AC, Robinson ES, Robbins TW. Dissociable effects of noradrenaline, dopamine, and serotonin uptake blockade on stop task performance in rats. Psychopharmacology (Berl). Aug 2009;205(2):273-83. doi:10.1007/s00213-009-1537-0

62. Obeso I, Wilkinson L, Jahanshahi M. Levodopa medication does not influence motor inhibition or conflict resolution in a conditional stopsignal task in Parkinson's disease. Exp Brain Res. Sep 2011;213(4):43545. doi:10.1007/s00221-011-2793-x

63. Overtoom CC, Verbaten MN, Kemner C, et al. Effects of methylphenidate, desipramine, and L-dopa on attention and inhibition in children with Attention Deficit Hyperactivity Disorder. Behav Brain Res. Oct 17 2003;145(1-2):7-15. doi:10.1016/s0166-4328(03)00097-4 64. Obeso I, Wilkinson L, Casabona E, et al. Deficits in inhibitory control and conflict resolution on cognitive and motor tasks in Parkinson's disease. Exp Brain Res. Jul 2011;212(3):371-84. doi:10.1007/s00221-011-2736-6

65. Nombela C, Rittman T, Robbins TW, Rowe JB. Multiple modes of impulsivity in Parkinson's disease. PLoS One. 2014;9(1):e85747. doi:10.1371/journal.pone.0085747

66. Jabbari E, Holland N, Chelban V, et al. Diagnosis Across the Spectrum of Progressive Supranuclear Palsy and Corticobasal Syndrome. JAMA Neurol. Mar 1 2020;77(3):377-387.

doi:10.1001/jamaneurol.2019.4347

67. Ramoz N, Boni C, Downing AM, et al. A haplotype of the norepinephrine transporter (Net) gene Slc6a2 is associated with clinical response to atomoxetine in attention-deficit hyperactivity disorder (ADHD). Neuropsychopharmacology. Aug 2009;34(9):2135-42. doi:10.1038/npp.2009.39

68. Whelan R, Conrod PJ, Poline JB, et al. Adolescent impulsivity phenotypes characterized by distinct brain networks. Nat Neurosci. Jun 2012;15(6):920-5. doi:10.1038/nn.3092 
medRxiv preprint doi: https://doi.org/10.1101/2021.10.14.21264996; this version posted October 16, 2021. The copyright holder for this preprint (which was not certified by peer review) is the author/funder, who has granted medRxiv a license to display the preprint in perpetuity.

It is made available under a CC-BY 4.0 International license.

Table 1 Demographics (mean and standard deviation) of participants and clinical assessments.

\begin{tabular}{|c|c|c|c|c|c|c|}
\hline & \multicolumn{3}{|c|}{ Descriptive } & \multicolumn{3}{|c|}{$P$ values for pairwise tests } \\
\hline & HC & PD & PSP & $\begin{array}{l}\text { HC vs } \\
\text { PD }\end{array}$ & $\begin{array}{l}\text { HC vs } \\
\text { PSP }\end{array}$ & $\begin{array}{l}\text { PD vs } \\
\text { PSP }\end{array}$ \\
\hline Age (years) & $65.5(5.5)$ & $67.2(7.4)$ & 69.7 (7.7) & 0.66 & 0.164 & 0.52 \\
\hline $\begin{array}{l}\text { Education } \\
\text { (years) }\end{array}$ & $14.8(3.1)$ & $14(2.3)$ & $12.3(2.8)$ & 0.584 & 0.021 & 0.15 \\
\hline Male/Female & $13 / 11$ & $18 / 6$ & $8 / 6$ & 0.131 & 0.859 & 0.253 \\
\hline MMSE & $29.75(0.53)$ & $29.52(0.65)$ & $28.5(1.74)$ & 0.649 & $<0.001$ & 0.009 \\
\hline MoCA & $28.58(1.44)$ & $27.88(1.87)$ & $24(3.94)$ & 0.557 & $<0.001$ & $<0.001$ \\
\hline ACER-total & $97.71(3.25)$ & $95.25(3.6)$ & $87.21(7.17)$ & 0.153 & $<0.001$ & $<0.001$ \\
\hline Apathy Scale & $10.38(5.25)$ & $12.42(5.55)$ & $20(9.49)$ & 0.528 & $<0.001$ & 0.003 \\
\hline BIS & $55.71(9.56)$ & $58.69(10.21)$ & $63.86(12.44)$ & 0.591 & 0.063 & 0.316 \\
\hline $\begin{array}{l}\text { HADS- } \\
\text { depression }\end{array}$ & $2.83(2.84)$ & $4.25(2.79)$ & $7.43(4.27)$ & 0.281 & $<0.001$ & 0.012 \\
\hline HADS-anxiety & $4.29(3.53)$ & $5.17(3.16)$ & $6.57(3.2)$ & 0.634 & 0.111 & 0.424 \\
\hline RBDSQ & - & $5.38(3.69)$ & $3.07(1.82)$ & - & - & 0.036 \\
\hline $\begin{array}{l}\text { Disease } \\
\text { Duration (years) }\end{array}$ & - & $5.09(3.05)$ & $4.24(2.68)$ & - & - & 0.397 \\
\hline LEDD & - & $\begin{array}{c}646.6 \\
(509.53)\end{array}$ & $\begin{array}{l}323.57 \\
(389.4)\end{array}$ & & & 0.038 \\
\hline UPDRS-III & - & $28.21(12.21)$ & 33.07 (6.96) & - & - & 0.182 \\
\hline PSPRS & - & - & $30.79(9.11)$ & - & - & - \\
\hline
\end{tabular}

Group difference in sex was examined using chi-square test. A one-way ANOVA was used for group difference with post-hoc Tukey HSD p values provided for pairwise comparisons. RBDSQ, disease duration and UPDRS-III were compared with independent samples t-test between PD and PSP. MMSE: Mini-Mental State Examination, MoCA: Montreal Cognition Assessment, ACER: Addenbrooke's Cognitive Examination Revised, BIS: Barratt Impulsiveness Scale, HADS: Hamilton Anxiety and Depression Scale, RBDSQ: REM Sleep Behaviours Screening Questionnaire, LEDD: Levodopa equivalent daily dose, UPDRS: Unified Parkinson's Disease Rating Scale, PSPRS: Progressive Supranuclear Palsy Rating Scale. Significant $P$ values ( $P<0.0016$, equivalent to $P<0.05$ with Bonferroni correction) are highlighted in bold. 


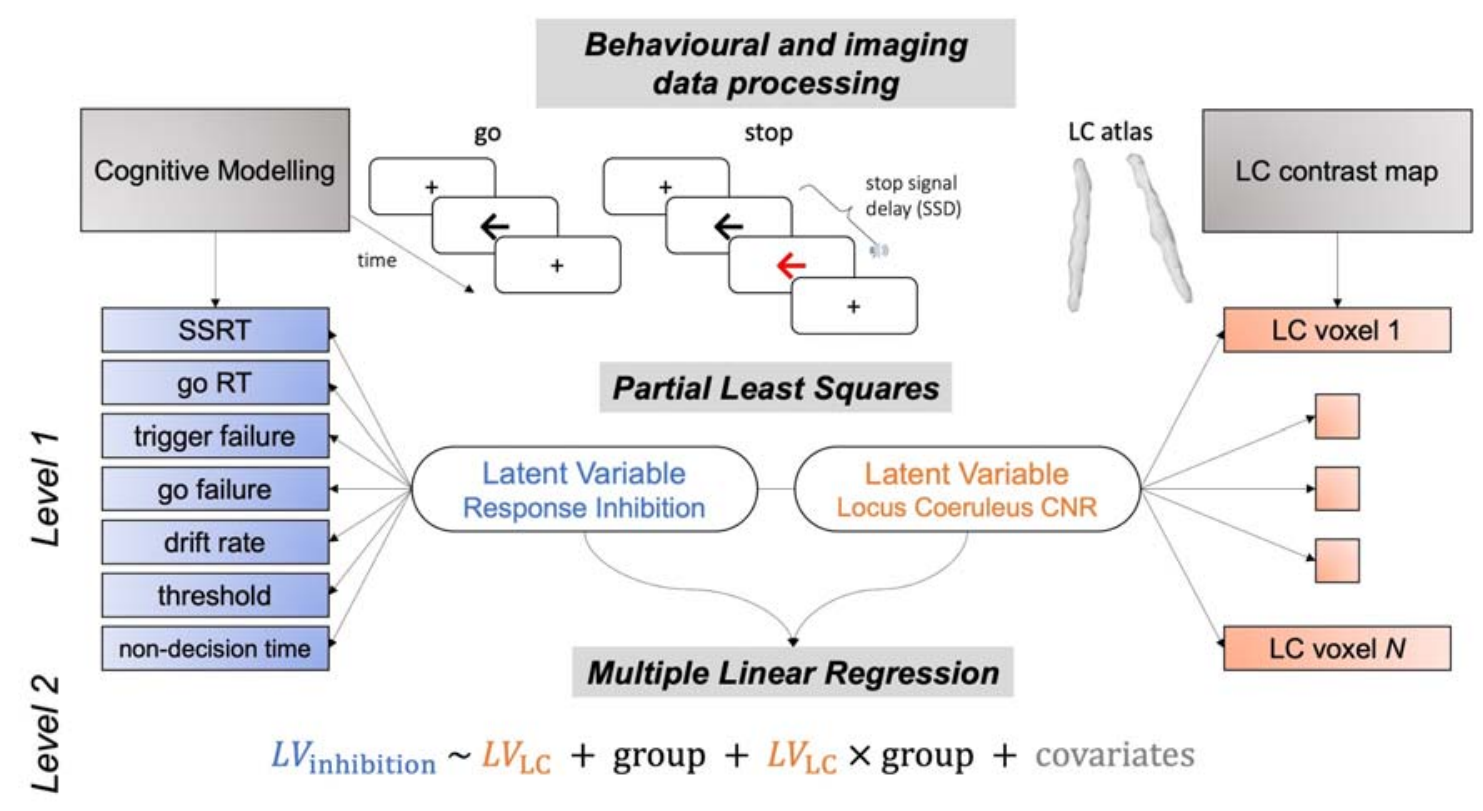

Figure 1 | Schematic representation of data analysis pipeline. The trial-by-trial stop signal task performance was subjected to a two parametric race model following ex-Gaussian and shifted Wald distributions. An array of behavioural parameters were estimated hierarchically from the models for both stop and go response, including stop-signal reaction time (SSRT), go reaction time (go RT), trigger failure, go failure, drift rate (v), response threshold (B) and non-decision time (t0). These parameters altogether provided more mechanistic understanding of response inhibition. The locus coeruleus (LC) integrity was assessed by computing voxel-wise contrast-to-noise ratio (CNR) and extracted using an independent $\mathrm{LC}$ probability atlas. The multivariate relationship between $\mathrm{LC}$ integrity and response inhibition was then examined using partial least squares using resulted behavioural and imaging matrices from previous data processing steps. Significant pairs of latent variables were identified with the permutation test. The contribution of $\mathrm{LC}$ in response inhibition was finally confirmed in linear regression models with individual subject loading scores on the inhibition latent variable as dependent variable, loading scores on the LC latent variable, group and nuisance covariates as predictors. 

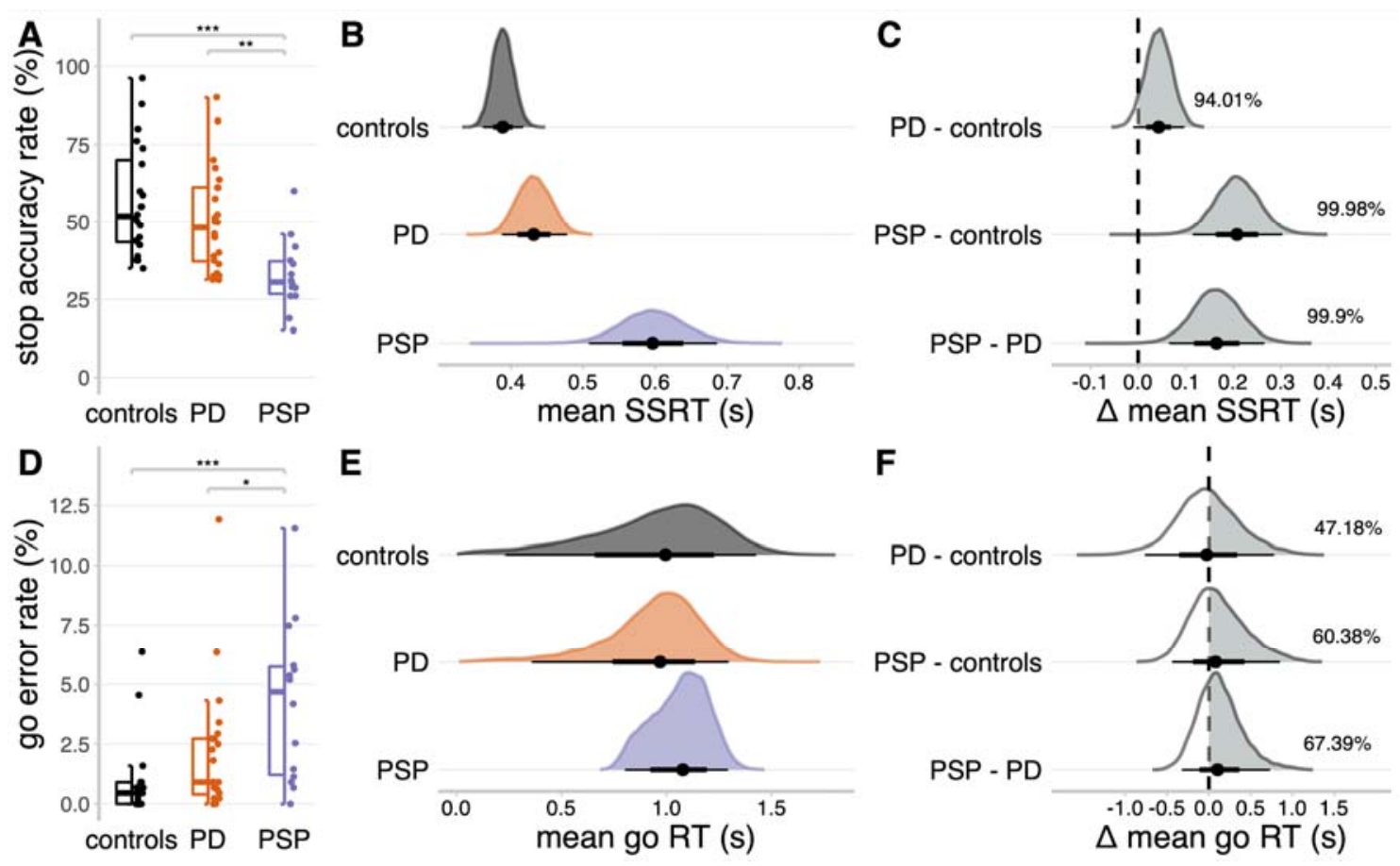

Figure 2 | Stop signal task performance. (A, D): Proportions of successful stop trials (A) and incorrect go responses (D). Asterisks represent the statistical significance of post-hoc Tukey's tests comparing groups: ***, $P<.001 ; * *, P<.01 ; *, P<.05$. (B, E): Posterior distributions of the mean stop signal reaction times (B) and mean go reaction times $(E)$. The black dots represent the medians; thick black line segments represent the $66 \%$ quantile intervals; thin black line segments represent the $95 \%$ quantile intervals. (C, F): Posterior distributions of group comparisons for the mean stop signal reaction time (C) and mean go reaction time (F). Percentages indicate the proportion of the posterior distribution that is strictly positive, i.e. the grey shaded area. 
A

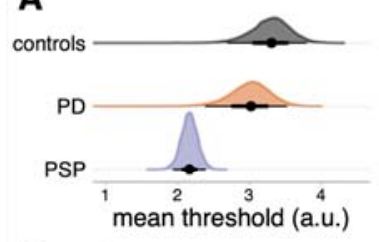

C
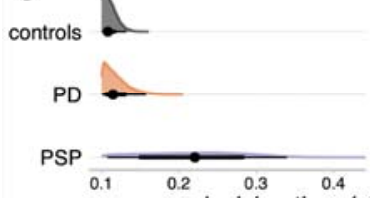
mean non-decision time (s)

E

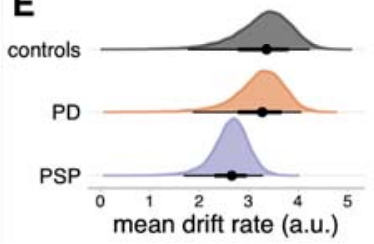

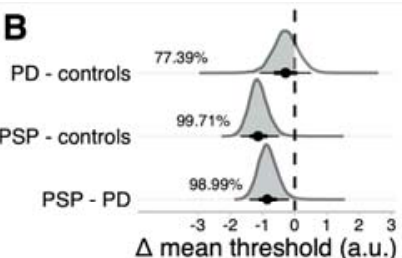
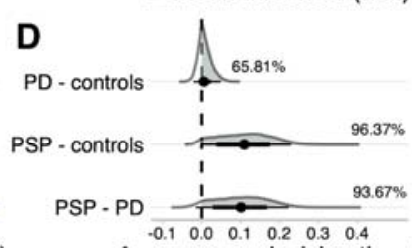

$\Delta$ mean non-decision time (s)

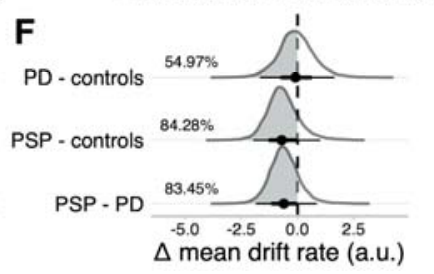

G

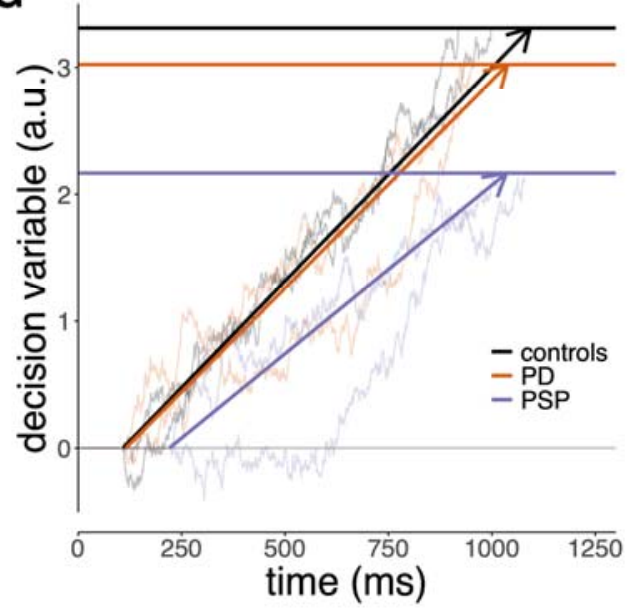

Figure 3 | Sequential sampling model of go responses. (A, C, E): Posterior distributions of mean threshold (A), mean non-decision time $(C)$, and mean drift rate $(E)$. The black dots represent the medians; thick black line segments represent the $66 \%$ quantile intervals; thin black line segments represent the $95 \%$ quantile intervals. (B, D, E): Posterior distributions of group comparisons for the mean threshold (B), mean non-decision time (D), and mean drift rate $(F)$. Percentages indicate the proportion of the posterior that is strictly negative (B, F) or positive (D), i.e. the grey shaded area. (G) Schematic illustration of the sequential sampling model. Evidence for a go response accumulates stochastically at a constant average rate (the drift rate) until a threshold is reached. To explain reaction times, the time taken by the accumulator to reach the threshold is offset by a constant non-decision time. The bold horizontal lines represent the posterior median estimates of the mean thresholds. The bold directed lines represent the posterior median estimates of the mean drift rate. The thin lines provide examples of simulated random walks. 
A

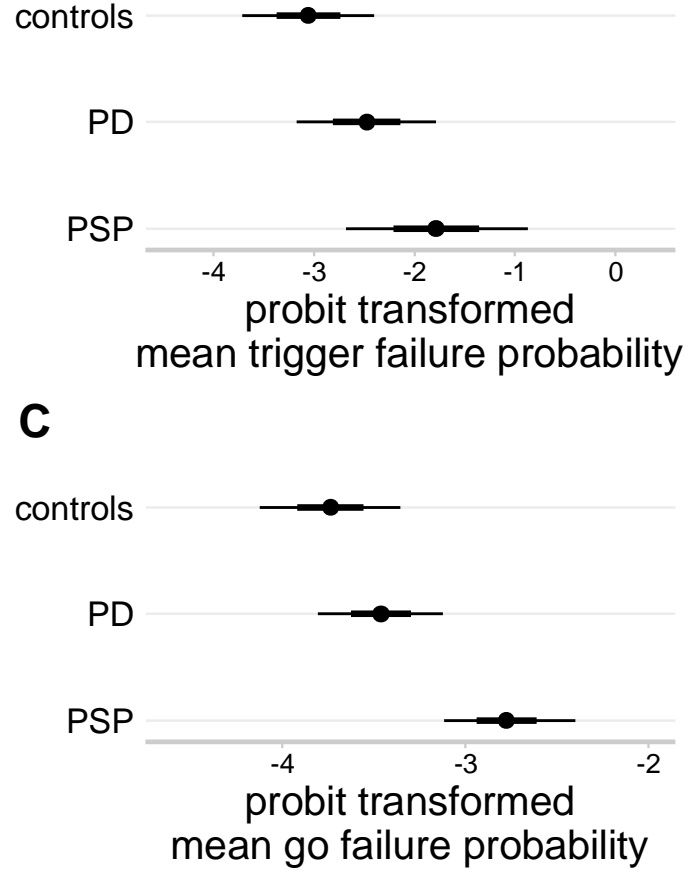

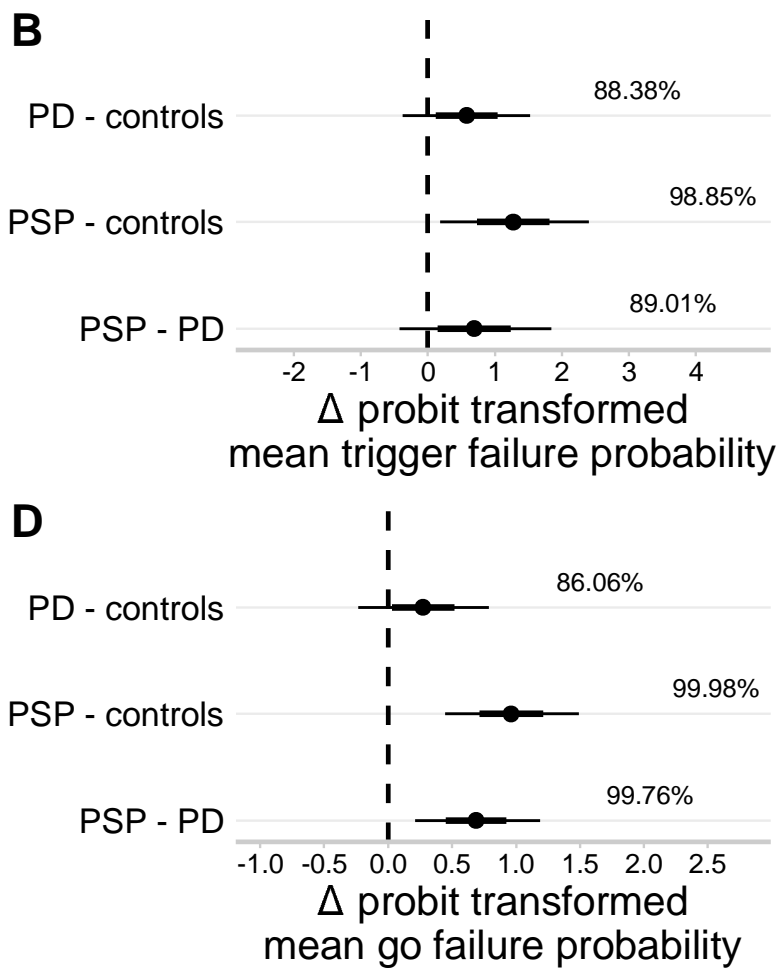

Figure 4 | Group-level means of attentional failure parameters. (A, C): Posterior distributions of probit transformed mean trigger failure probability (A), and probit transformed mean go failure probability (C). The black dots represent the medians; thick black line segments represent the $66 \%$ quantile intervals; thin black line segments represent the 95\% quantile intervals. (B, D): Posterior distributions of group comparisons for the probit transformed mean trigger failure probability $(B)$ and probit transformed mean go failure probability (D). Percentages indicate the proportion of the posterior that is strictly positive, i.e. the grey shaded area. Note that the probit function was used to project the attentional failure parameters from the probability scale $(0,1)$ to the real line $(-\infty, \infty)$. 
A
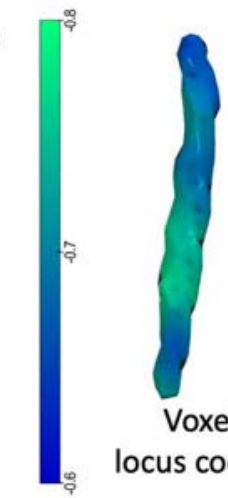

Voxelwise loadings on locus coeruleus CNR LV (a.u.)

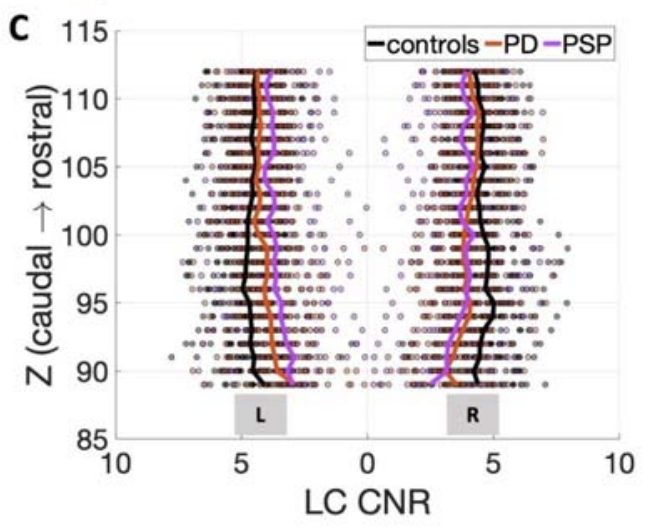

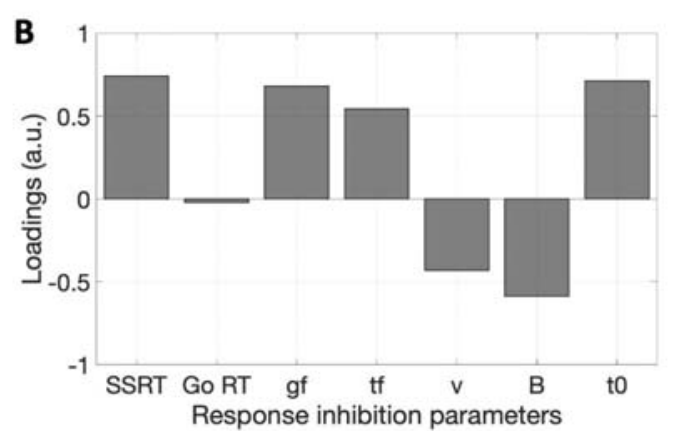

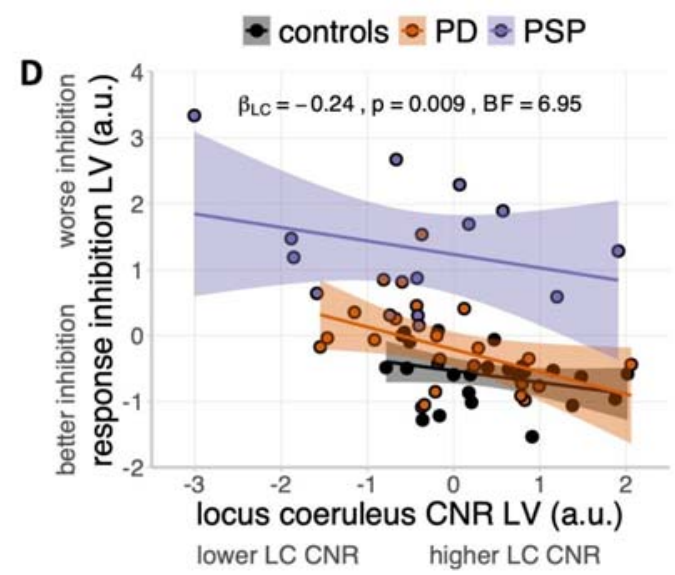

Figure 5 | The relationship of locus coeruleus integrity and response inhibition. As confirmed using partial least squares, a significant pair of latent variables was identified between voxel-wise $L C$ contrast and response inhibition parameters estimated from cognitive models. The spatial distribution of voxelwise LC loadings (A) and individual loadings on response inhibition latent variable (B) were presented. Negative LC loadings were associated with positive loadings on stop-signal reaction time (SSRT), go failure (gf), trigger failure (tf) and non-decision time (to), and negative loadings on drift rate (v) and response threshold (B). This suggested that impaired response inhibition is linked with reduced LC integrity seen in both PD and PSP patients (C). An overall relationship of LC integrity and response inhibition was further confirmed in the linear regression model consistent across all groups as supported by a significant main effect of $L C$ when including the group predictor in the model (D). Individual fitted lines for each group were presented with curved areas indicating $95 \%$ confidence intervals. 